\title{
A reforma do Estado no contexto latino-americano: comentários sobre alguns impasses e possíveis desdobramentos
}

\section{Introdução}

A maioria dos países latino-americanos se encontra diante de mais uma encruzilhada histórica: incorporar-se ao processo de integração das economias mundiais a partir de uma postura pró-ativa ampliadora dos limites do possível, mesmo que dentro de um papel limitado e secundário, ou permanecer à margem das macrotransformações em curso, em virtude da sua incapacidade de processar seus conflitos internos. Este dilema é, no entanto, agravado pela conjunção dos seguintes fatores: a intensificação da concorrência no âmbito do comércio internacional; a cristalização de dianteiras no campo da revolução tecnológica; o agravamento do processo de exclusão social (com a conseqüente elevação dos custos de seu equacionamento); a permanência de problemas estruturais do setor público capazes de comprometer o precário e caro ajuste macroeconômico recém conquistado; a dificuldade de produção de consensos mínimos capazes de assegurar condições de institucionalidade ao confronto de interesses sociais. Além disto, deve-se destacar também o posicionamento pelo sistema financeiro internacional das regiões merecedoras de investimentos a partir de critérios como rentabilidade, segurança jurídica, livre mobilidade do capital, abertura da economia, custos de transação, qualidade da infraestrutura e da mão-de-obra etc.

A globalização, nas suas mais diversas dimensões (financeira, cultural, econômica, demográfica e tecnológica, entre outras), vem produzindo corporações cada vez mais competitivas, ágeis, flexíveis e poderosas, capazes de superar muitos países conforme o ângulo da análise. Em contrapartida, o Estado encontra-se em xeque, bem como seu padrão de interações com a sociedade, de onde se espera que emane seu poder.

Especialista em Políticas Públicas e Gestão Governamental e professor da PUC-MG 
Rediscutem-se suas áreas de atuação, em que níveis de regulação coletiva deve atuar (de que forma), bem como sua capacidade de governar-se (governance).

O texto apresentado a seguir é uma reflexão sobre a Reforma do Estado na América Latina, em especial no que se refere a seu aparato institucional — a "máquina administrativa." As opções dos países da região, frente às alternativas anteriormente mencionadas, passam necessariamente pelos desdobramentos da forma pela qual (re)definirem o modus operandi de seus respectivos serviços públicos, bem como pelo sucesso que obtiverem no desenvolvimento de economias de mercado. Trata-se, portanto, de construir um Estado forte, consistente, com uma economia dinâmica competitiva, da qual é parceiro e regulador, além de desempenhar de forma adequada suas funções clássicas (administração da provisão de serviços prestados direta ou indiretamente e gestão dos direitos sociais básicos).

O protagonismo das economias de mercado aponta para a centralidade do funcionamento do setor público, condicionante e modelador das relações sociais de produção que regulam a dinâmica econômica e social das nações. A problematização dos esforços modernizadores em curso e o exame das dificuldades e condições necessárias para aumento das probabilidades de êxito constituem o referencial desta reflexão.

\section{Considerações preliminares}

A crise do Estado nos anos 80 se deu de forma entrelaçada com os processos de transição para a democracia, com o esgotamento do padrão de desenvolvimento fundado na substituição de importações, com o colapso das contas externas, com a crise econômico-financeira e com a desestruturação do setor público (o aparato de Estado) na maioria dos países latino-americanos. As chamadas reformas de primeira geração atacaram este quadro e foram constituídas por medidas que "apresentaram três características comuns:

"Primeiro, as decisões iniciais de reforma se concentraram especialmente na modificação das regras que determinavam o comportamento macroeconômico.

Segundo, as reformas macroeconômicas puderam ser adotadas pelo Poder Executivo em um relativo isolamento do resto do sistema político, sua implementação tendo sido administrativamente simples.

Terceiro, as novas medidas buscaram desmantelar muitos organismos públicos existentes, sem que esses tivessem que ser substituídos imediatamente por novos organismos". (NAIM, 1994a:5) 
Quadro 1: Metas, objetivos e instituições em distintas

fases de reformas econômicas

\begin{tabular}{|c|c|c|}
\hline & Primeira fase & Segunda fase \\
\hline Prioridades & $\begin{array}{l}\text { Reduzir a inflação } \\
\text { Restabelecer o crescimento }\end{array}$ & $\begin{array}{l}\text { Melhorar as condições } \\
\text { sociais } \\
\text { Melhorar a competitividade } \\
\text { internacional } \\
\text { Manter a estabilidade macro- } \\
\quad \text { econômica }\end{array}$ \\
\hline $\begin{array}{l}\text { Estratégia da } \\
\text { reforma }\end{array}$ & $\begin{array}{l}\text { Modificar as regras } \\
\text { macroeconômicas } \\
\text {. Reduzir o tamanho } \\
\text { e âmbito do Estado } \\
\text {. Desmontar instituições de } \\
\text { protecionismo e estatismo }\end{array}$ & $\begin{array}{l}\text { Criação e reabilitação insti- } \\
\text { tucional } \\
\text {. Elevar a competitividade do } \\
\text { setor privado } \\
\text {. Reformar a produção, finan- } \\
\text { ciamento e prestação de ser- } \\
\text { viços de saúde, educação e } \\
\text { outros serviços públicos } \\
\text { Criar "instituições econômicas } \\
\text { de capitalismo" } \\
\text { Desenvolver nova "inserção } \\
\text { econômica internacional" }\end{array}$ \\
\hline $\begin{array}{l}\text { Instrumentos típicos } \\
\text { (objetivos de refor- } \\
\text { ma) }\end{array}$ & $\begin{array}{l}\text { Cortes orçamentários drás- } \\
\text { ticos e reforma fiscal } \\
\text {. Liberalização de preços } \\
\text { (incluindo o tipo de câmbio } \\
\text { e a taxa de juros) } \\
\text {. Liberalização do comércio in- } \\
\text { ternacional e do investimen- } \\
\text { to estrangeiro } \\
\text {. Desregulamentação do } \\
\text { setor privado } \\
\text { Criação de "fundos sociais } \\
\text { de emergência" à margem } \\
\text { dos ministérios sociais } \\
\text { Privatizações "fáceis" (com- } \\
\text { panhias aéreas, hotéis e algu- } \\
\text { mas empresas manufatureiras) }\end{array}$ & $\begin{array}{l}\text { Reformar a legislação e práti- } \\
\text { cas trabalhistas } \\
\text {. Reformar a Administração } \\
\text { Pública } \\
\text {. Reformular estrutura orga- } \\
\text { nizacional do Governo } \\
\text { Central } \\
\text {. Modernizar e melhorar a } \\
\text { administração da justiça } \\
\text {. Modernizar a capacidade } \\
\text { reguladora (dos serviços } \\
\text { privatizados e de outros } \\
\text { monopólios, supervisão } \\
\text { antitrust e antidumping, se- } \\
\text { tor financeiro, meio ambien- } \\
\text { te, trabalho etc) } \\
\text {. Melhorar a capacidade } \\
\text { para arrecadar impostos } \\
\text { Conversão e reestrutura- } \\
\text { ção setorial (indústria, agri- } \\
\text { cultura, setor bancário, } \\
\text { serviços, mineração etc) } \\
\text { Privatizações "complexas" } \\
\text { (infra-estrutura, serviços, } \\
\text { mineração, outros serviços } \\
\text { públicos) } \\
\text { Desenvolver a capacidade de } \\
\text { fomento às exportações } \\
\text { - Reestruturar as relações } \\
\text { entre governo central e os } \\
\text { governos regionais } \\
\text {. Modernizar o Congresso }\end{array}$ \\
\hline
\end{tabular}

Fonte: NAIM, 1994a: 11-13 


\begin{tabular}{|c|c|c|}
\hline & Primeira fase & Segunda fase \\
\hline Principais atores & $\begin{array}{l}\text { Presidência } \\
\text {. Gabinete econômico } \\
\text {. Banco Central } \\
\text {. Instituições financeiras } \\
\text { multinacionais } \\
\text {. Grupos financeiros } \\
\text { privados e investidores } \\
\text { estrangeiros de carteira }\end{array}$ & $\begin{array}{l}\text { Presidência e gabinete } \\
\text {. Congresso } \\
\text {. Burocracia pública } \\
\text {. Poder Judiciário } \\
\text {. Sindicatos } \\
\text {. Partidos políticos } \\
\text {. Meios de comunicação } \\
\text {. Governos regionais } \\
\text {. Setor privado }\end{array}$ \\
\hline $\begin{array}{l}\text { Impacto público } \\
\text { de reforma }\end{array}$ & $\begin{array}{l}\text { Imediato } \\
\text { Alta visibilidade pública }\end{array}$ & $\begin{array}{l}\text { A médio e longo prazo } \\
\text {. Baixa visibilidade pública }\end{array}$ \\
\hline $\begin{array}{l}\text { Complexidade técnica } \\
\text { e administrativa de } \\
\text { reformas }\end{array}$ & . Moderada a baixa & . Muito alta \\
\hline $\begin{array}{l}\text { Características de } \\
\text { custos políticos }\end{array}$ & $\begin{array}{l}\text { Constituem "correções } \\
\text { temporais" cujos custos } \\
\text { se distribuem amplamente } \\
\text { entre toda a população }\end{array}$ & $\begin{array}{l}\text { Implicam eliminação per- } \\
\text { manente de vantagens } \\
\text { especiais de que tradicio- } \\
\text { nalmente têm gozado gru- } \\
\text { pos específicos. }\end{array}$ \\
\hline $\begin{array}{l}\text { Principal desafio } \\
\text { para o governo }\end{array}$ & $\begin{array}{l}\text { Gestão macroeconômica } \\
\text { por elites tecnocráticas } \\
\text { isoladas }\end{array}$ & $\begin{array}{l}\text { Desenvolvimento alta- } \\
\text { mente dependente do } \\
\text { desempenho de gerentes } \\
\text { médios dentro do setor } \\
\text { público }\end{array}$ \\
\hline
\end{tabular}

Fonte: NAIM, 1994a: 11-13

Neste sentido, observou-se um processo de desmantelamento e desmanche institucional, agravado pelas debilidades e incapacidades do Estado em desenvolver as instituições próprias ao funcionamento das economias de mercado (ex: órgãos reguladores e órgãos protetores da concorrência e dos consumidores).

O mosaico latino-americano da segunda metade dos anos 90 indica que os desafios enfrentados agora, para além da consolidação do ajuste macroeconômico, são de natureza diversa, situando-se no plano da regeneração de instituições duramente afetadas pelas crises mencionadas ou na sua própria criação para atender às necessidades do novo contexto. As chamadas reformas de segunda geração emergem, então, apontando na direção de transformações estruturais cuja dinâmica de implementação demanda um conjunto de competências distintas dos requisitos dos choques macroeconômicos, conforme mostram os quadros $1 \mathrm{e}$ 2 (NAIM, 1994a: 11-13). Tratam-se de capacidades cujo desenvolvimento faz parte dos problemas.

A integração da estabilização com políticas públicas que assegurem simultânea e interdependentemente maior competitividade, eqüidade 
social, crescimento e desenvolvimento indica a importância de se transformar o Estado a partir de uma estratégia multifacetada, seletiva e progressiva, dados as multiplicidades e os graus de resistência a serem enfrentados. Há, no entanto, ressalvas a serem consideradas. "Depois de tudo, e a diferença das mudanças políticas caracteriza a primeira fase, o custo das mudanças institucionais recai particularmente sobre grupos específicos que, na raiz das reformas, podem perder para sempre as vantagens e privilégios que têm tradicionalmente desfrutado."(NAIM, 1994a: 12).

Somente uma administração pública engendrada em bases mais profissionais e meritocráticas possui condições de levar a cabo esta tarefa. Atrair, recrutar, fixar e motivar os quadros portadores destas competências (ou das potencialidades de desenvolvê-las) não é simples. Na verdade, é um complexo ingrediente de um esforço de renovação permanentemente ameaçado pelo espectro do populismo (com suas práticas clientelistas e fisiológicas) e do corporativismo conservacionista incrustrado na máquina administrativa.

\section{Governance e accountability:traduttore, traditore}

A palavra governance não possui tradução em português. O anglicismo governança não reproduz seu significado e conteúdos possíveis, o que não significa que deixem de existir por ausência de designação adequada. É o mesmo problema que ocorre com accountability. "Responsabilização" e "prestação de contas" não refletem o conteúdo e a realidade que expressam.

"Accountability está no coração da boa governança (governance) responsável por suas ações. No nível político, ela significa fazer os governantes responsáveis (accountable) perante os governados, tipicamente através da possibilidade de se contestar o poder político”. (WORLD BANK, 1994: 12)

Certamente trata-se de um problema de cultura que a linguagem, enquanto um de seus elementos fundantes, não encontrou formas de expressar.

Accountability é uma importante categoria de análise para a compreensão, não apenas da problemática da crise do Estado na América Latina, como também, e especialmente, para instrumentalizar ações e programas de reestruturação do setor público nos níveis macro e micro.

O Banco Mundial apresentou uma interessante desconstrução do conceito, relacionando-o com as esferas micro e macro, interligando-as através do recorte da descentralização. 
No nível macro,

“(...) Os objetivos econômicos da responsabilização (accountability) pública incluem assegurar a congruência entre política pública e implementação efetiva e a alocação e uso eficientes dos recursos públicos. (...) Dois aspectos principais da responsabilização (accountability) no nível macro são particularmente relevantes (...): responsabilização financeira e responsabilização pela performance econômica geral.

No nível micro, a preocupação básica é com a eficiência tanto no investimento como na produção e na entrega de bens e serviços no setor público. A responsabilização (accountability) no nível micro pode reforçar a responsabilização no nível macro quando há competição (exemplo: mecanismos de "saída" — exit) ou participação (exemplo: mecanismos de "vocalização" — voice)." (World BANK, 1992: 13-22)

Este marco conceitual, tão pouco familiar aos países de colonização ibérica, é bastante esclarecedor das dificuldades até mesmo de elaboração dos problemas relacionados com a reforma do Estado.

Algo semelhante ocorre com a palavra governance. As reformas de segunda geração perpassam justamente a discussão sobre governance, seja do ponto de vista político, institucional ou gerencial.

“(...) normalmente, governance é usado como um 'conceito guarda-chuva' capaz de acolher processos e objetivos políticos esquivos e mal definidos, bem como objetivos desejáveis e preferências de valor." (FRISCHTAK, 1994: 1)

O foco desta discussão é a questão da capacidade do governo "dirigir os assuntos de Estado" (LEISINGER, 1996: 46) nesta perspectiva, abrangendo o processo de tomada de decisões, a implementação de políticas e o desenvolvimento de mecanismos de controle. É interessante, no entanto, explorar esta conceituação e expandir suas recentes interpretações com a finalidade de delimitar melhor o campo de análise proposto.

"Governance refere-se a capacidade, assim como governo refere-se a abrangência. Governance é a quantidade dinâmica de governo, este último entendido como as normas, processos, instrumentos e instituições que conformam o aparato estatal. Governance é também a faculdade de dirigir, que é manifestada na condução estatal das políticas. Mais importante, porém, é o fato de governance se referir ao poder. Enquanto o conjunto de instituições de governo é intrinsecamente destituído de poder, sendo, de fato, consumidor de poder, governance refere-se precisamente à capacidade 
de gerar, de desenvolver o poder da sociedade; e o exercício da governança (governance) é, antes de tudo, o exercício do poder estatal." (FrischTAK, 1994: 28)

O próprio Banco Mundial, a partir da década de 90, tem dedicado bastante atenção ao tema, a partir do entendimento da importância da categoria governance, no sentido da forma como o poder é exercido.

"O Banco Mundial identificou três aspectos distintos da governance: (i) a forma do regime político, (ii) o processo da autoridade que é exercido na administração dos recursos econômicos e sociais de um país para o desenvolvimento e (iii) a capacidade dos governos de desenhar, formular e implementar políticas e de cumprir funções." (WoRLD BANK, 1994: xiv)

Estas definições podem ser complementadas pela distinção entre a administração pública e o governo propriamente dito:

“(...) é recomendável fazer uma distinção entre o setor público, constituído por aquela parte da economia que é controlada pelo Estado, e o governo, que compreende as autoridades públicas o Executivo, o Legislativo e o Judiciário - e a interação destas autoridades com os partidos políticos, os sindicatos e outras organizações dos cidadãos através das quais o processo governamental é adequadamente canalizado e conduzido." (TomAssini, 1994: 32)

O fato é que tanto o World Bank (Burki and EDwARDS, 1996: 36) quanto o Inter-American Development Bank (TomAssinI, 1994: 38) ao longo da década de 90 incorporaram em suas respectivas agendas a modernização do serviço público como componente indispensável à "boa gestão do desenvolvimento."(LEISINGER, 1996: 46)

\section{As reformas entrelaçadas}

Embora as reformas macroeconômicas sejam requisitos para a retomada do processo de crescimento na América Latina, fica cada vez mais clara a existência de íntimas conexões entre seu processo de consolidação e as reformas institucional e social. A exclusão e a desigualdade social constituem um dos maiores vetores de instabilidade das jovens democracias do continente, e seu enfrentamento não pode prescindir de reformas profundas no aparato governamental. No núcleo destas interações permanece uma lacuna referente à ausência de uma política orgânica de administração pública (KLIKSBERG, 1992: 11), que condiciona e medeia o conjunto de todas as demais políticas públicas. 
Esta é uma questão particularmente relevante quando se analisam as interfaces da reforma institucional com as reformas econômicas e sociais. Os planos de estabilização, ao dissiparem a névoa inflacionária, revelaram realidades marcadas por desigualdades insustentáveis. Em diversos casos sua adoção resultou, num primeiro momento, no agravamento do processo de ruptura de equilíbrios sociais instáveis e precários, mas que funcionavam como amortecedores da crise social.

As fronteiras entre as duas gerações de reforma são tênues. Na verdade deveriam ser entendidas e implementadas como processos simbióticos e interdependentes, embora distintos. Quanto maior a distância entre ambas, maiores as resistências à sua implementação (em especial no que se refere às segundas) e maiores os riscos de comprometimento dos avanços alcançados.

O caráter multifacetado e fragmentado das reformas de segunda geração traduz-se na necessidade de uma abordagem aberta, também heterogênea, capaz de conciliar e/ou operar conjuntamente distintos matizes e ethos.

As formas de lidar com a problemática da Reforma do Estado de acordo com Naim (1994a) podem ser agrupadas em três abordagens sínteses: gerencial-tecnocrática, econômico-financeira e política. Somente se encaminhadas de forma integrada será possível a obtenção de uma melhor compreensão dos graves problemas colocados e um apoio substantivo ao desenvolvimento de (novos) instrumentos necessários para seu enfrentamento.

Isto significa a manutenção de um sistemático e contínuo esforço de persuasão e convencimento do titular do Executivo, da área econômica, da classe política, da cúpula do Judiciário e dos formadores de opinião de que a consolidação da democracia e da estabilização macroeconômica não podem prescindir de um investimento da nação na implementação da reforma do Estado. E esta tarefa exige os melhores talentos que os países da região são capazes de mobilizar para superar este complexo desafio.

A mudança de paradigma em relação ao papel do Estado, em que pese o conjunto de controvérsias persistentes, aponta na direção de uma focalização do desenvolvimento de (novas e velhas) capacidades do setor público.

"Alterações significativas são necessárias para que se possa mudar um paradigma de governo excessivamente intervencionista, na direção de um paradigma no qual o papel do setor público é criar um ambiente propício para a ação do setor privado, regular onde necessário e assegurar a entrega eficiente de serviços públicos básicos." (WoRLD BANK, 1994) 
Há de se considerar, no entanto, o risco de se acomodar em um quadro de adjustment fadigue, em decorrência das dificuldades de se processarem as reformas de segunda geração, em geral de caráter estrutural e redefinidoras de regras freqüentemente responsáveis pelos desequilíbrios e crises típicos das décadas anteriores.

Na verdade, observa-se uma contradição, um mismatch, the paradox of the Adjusting State and the Conceptual Space for Governance.

“(...) o paradoxo era que a redução do tamanho do Estado e da abrangência de sua interferência no mercado parecia implicar uma capacidade estatal expandida. $O$ fato de essa capacidade, na sua forma básica, ser raramente encontrada na maioria dos países em desenvolvimento, tendo, assim, que ser construída e inventada em um contex to de redução acelerada dos recursos, é uma das ironias perversas do ajustamento." (FRISCHTAK, 1994).

\section{O desafio da implementação da Reforma}

A cultura de planejamento e de projetos desenvolvida nas décadas de 50, 60 e 70 na América Latina, sob a influência da Comissão Econômica para América Latina e Caribe - CEPAL e das agências multilaterais de fomento (então fortemente defensoras do planejamento enquanto instrumento para a superação do subdesenvolvimento) já não existe mais, salvo marginalmente. As reformas de primeira geração guardam entre si um visível parentesco, descendendo todas em maior ou menor escala das formulações do chamado "Consenso de Washington". Já no campo das reformas de segunda geração permanece a indeterminação, seja sobre rumos, estratégias, métodos e, last but not least, sustentabilidade.

A primeira dificuldade reside no entendimento que se tem do problema. A manutenção de uma perspectiva de conjunto, mesmo que operacionalmente difícil, é importante para a organização e monitoramento do processo.

"Os problemas na performance das burocracias públicas resultam de uma complexa mistura de fatores políticos, econômicos, culturais e organizacionais, mistura essa que limita a efetividade daquelas soluções que são inspiradas por apenas uma daquelas facetas e ignoram as outras." (NAIM, 1994b).

Considerar estas múltiplas dimensões não é, no entanto, tarefa simples. O enfrentamento simultâneo de interesses cristalizados e incrustrados no Estado, a partir de comportamentos de rent-seeking, forjados ao longo de séculos, é muito difícil, seja do ponto de vista político (as ações de bloqueio e/ou veto são muito mais fáceis que o esforço de aprovação de 
reformas estruturais), econômico (a multiplicidade de fronts acaba resultando na pulverização de recursos e comprometimento de resultados) ou gerencial (a heterogeneidade dos níveis de complexidade dos problemas requer distintas abordagens em prejuízo da focalização indispensável para seu equacionamento).

Um enfoque compreensivo da problemática da reforma é também desejável especialmente no que se refere à estruturação do processo de sua implementação.

"Os elementos principais de um processo amplo de reformas são, em primeiro lugar, a elaboração de uma concepção precisa do papel do funcionalismo público e, com base neste papel ótimo, o desenvolvimento de um plano de reforma compreensivo (um plano que delimita os mecanismos específicos e necessários de reforma, esclarece os vínculos entre esses mecanismos e explicita a relevância de medidas de curto prazo para os objetivos de longo prazo); em segundo lugar, a racionalização das regras e regulamentações para o funcionalismo público (esforço legislativo); em terceiro lugar, o desenho de sistemas administrativos modernos (baseados em abordagens da administração do setor privado); e, em quarto lugar, a implementação do programa." (SHIHATA, 1994)

Este didático etapismo esbarra, no entanto, na forma como se organizam as administrações públicas latino-americanas e na forma de composição política dos governos. Não há um núcleo decisório capaz de sediar esta perspectiva coordenadora, excluindo-se o próprio Gabinete do Executivo ou o comando da área econômica, ambos já bastante absorvidos por outras (e mais decisivas e urgentes) atribuições.

$\mathrm{O}$ fato de estas reformas (previdenciária, social, administrativa, tributária e política, entre outras) se processarem no contexto de regimes democráticos precisa ser adequadamente levado em conta, uma vez que são intrinsecamente conflitivas e disruptivas, além de produzirem ganhos coletivos apenas no médio e longo prazos (e prejuízos particulares imediatos). Trata-se de "desprivatizar o Estado", de recuperar seu ethos republicano. Além disso, parte das resistências a serem superadas encontram-se solidamente instaladas no seio do aparato governamental (caso das corporações situadas no Judiciário, Legislativo, Tribunais de Contas, Ministério Público e Fiscalização), freqüentemente com amparo legal.

\section{Caminhos cruzados}

Os potenciais interessados na implementação das chamadas reformas estruturais são vários e obedecem a distintas lógicas e racionalidades, nem sempre convergentes. Compreender o campo destas forças, 
dificilmente convergentes (este é um dos desafios), é indispensável para a avaliação das possíveis alianças sustentadoras de esforços de governo nesta direção.

\subsection{A área econômica}

O endereçamento institucional da coordenação da reforma (geralmente em ministérios ou secretarias de administração, recursos humanos ou função pública) precisa ser alinhado necessariamente com o comando do governo e, particularmente, com o núcleo da área econômica. O vetor da estabilização inclui equilíbrio orçamentário, ênfase no aumento da receita, recuperação da instrumentalidade do orçamento, austeridade financeira, foco na natureza da despesa, auditoria de performance, transparência dos gastos, contratação de resultados etc. Esta é a mais poderosa plataforma para o desenvolvimento das reformas, desde que sua condução não fique restrita aos protagonistas dos planos de estabilização. A Reforma precisa ganhar o governo.

No contexto de rigidez das despesas típicas dos orçamentos públicos da América Latina, os remanejamentos de recursos se processam mediante cortes e não através de realocações explícitas. Isto significa que o comprometimento da área econômica com a disponibilização dos meios e condições para a operacionalização da reforma, bem como seu envolvimento, supervisão e comprometimento, é crucial para a sustentabilidade do processo.

\subsection{A burocracia pública}

O vetor endógeno, constituído pelas elites burocráticas do Estado (carreiras jurídicas, diversos tipos de fiscalização e cúpula do aparato policial), é outro segmento a ser considerado. Não possui, no entanto, condições nem projetos suficientes para alavancar as reformas. Faltalhes lastro e transcendência política, sem mencionar as eventuais deformações corporativas que eventualmente assolam estas categorias. Possuem também uma rede de relações e compromissos com os demais setores do funcionalismo (professores, saúde, força pública etc) que dificultam sua abertura ao controle social, bem como a efetiva representação do interesse público.

Os demais setores do funcionalismo, mesmo aqueles desvinculados de práticas predatórias em relação ao interesse público, não possuem apoio popular e poder de barganha para atuarem pró-ativamente na problematização das reformas (ao contrário dos países centrais onde as entidades de classe dos servidores são co-participantes deste processo). 
A exceção são os profissionais das estatais e suas entidades representativas, mas que também não têm conseguido desenvolver um padrão de atuação distinto do "defensivismo" típico de setores pouco habituados com a concorrência.

\subsection{O campo empresarial}

Uma interlocução que se renova é a relacionada com o setor produtivo. O padrão histórico - incentivos fiscais, crédito barato, barreiras alfandegárias, tributos reduzidos, socorro financeiro, distribuição discricionária de concessões etc. — permanece, mas começa a ser questionado por forças vinculadas a uma economia de mercado competitiva, que valoriza a concorrência, a preocupação com o respeito às saudáveis regras do jogo, a modernização das relações de trabalho e a segurança e credibilidade do sistema jurídico.

É neste contexto que se observa uma crescente preocupação, por parte dos investidores e organismos de fomento, com o ambiente econômico dos países latino-americanos. E isto inclui as regras de funcionamento das economias de mercado destes países, a chamada "corporate governance - the framework of laws, regulatory institutions, and reporting requirements that condition the way the corporate sector is governed." (WORLD BANK, 1994) — assim como o posicionamento de países, estados e prefeituras em termos de credibilidade na gestão dos recursos públicos e atratividade de investimentos.

\subsection{A sociedade civil}

A sociedade civil organizada e as chamadas organizações nãogovernamentais (ONGs) são protagonistas importantes nestes processos, ainda que com atuação restrita aos seus objetivos pontuais ou, na melhor das hipóteses, setoriais. Sua atomização e heterogeneidade dificultam o acúmulo de capital político para uma atuação articulada no plano mais macro. Ainda assim são atores com crescente peso na agenda decisória, em especial com a disseminação dos chamados voice mechanisms no âmbito dos processos de implementação de políticas públicas.

Mas, quando obtêm sucesso nos processos de mobilização social sobre as questões em torno da qual se organizam (meio ambiente, fome, corrupção, criança, terra, entre outras), há uma efetiva influência de seus pontos de vista sobre o processo decisório do governo. Esta é, em grande parte, a percepção das agências multinacionais de fomento, que passaram a incentivar a incorporação da participação das ONGs em programas que financiam, como mecanismos de avaliação e controle da produtividade dos gastos. 


\subsection{O desenvolvimento tecnológico}

A tecnologia e o desafio da competitividade internacional constituem um outro importante vetor a ser considerado. São inexoráveis, irreversíveis e ... velozes. A revolução tecnológica vem proporcionando incessantes reduções nos custos e um aumento na velocidade das transações. A pressão da concorrência internacional tem produzido inovações tecnológicas em diversas áreas da vida econômica e social, inclusive no setor público (ainda que mais lentamente). A adoção de tecnologias pervasivas como a microeletrônica e a telemática estão possibilitando ganhos de produtividade e o desenvolvimento de ferramentas gerenciais que estão revolucionando a gestão empresarial e a administração pública. A mídia, com seu considerável poder de pautar a agenda nacional, mudou completamente de natureza (ex: TV a cabo).

As grandes organizações - como as integrantes dos governos federal, estadual e municipal - têm oportunidades de produzir expressivos saltos de quantidade e qualidade nos serviços prestados à população. Aárea pública é estruturada em torno de um restrito conjunto de sistemas (arrecadação, execução orçamentária financeira, pessoal, dados estatísticos, comunicações etc). Mesmo no campo das tecnologias gerenciais, muitas inovações possuem amplo potencial de incorporação ao setor público. Uma reforma progressista, orientada para a simplificação, modernização e publicização da gestão pública, e intensiva em recursos tecnológicos, tem a seu favor os ventos da história.

\subsection{As elites políticas}

“(...) uma distinção clara deve ser traçada entre aquelas que constituem políticas do estado e aquelas que constituem políticas governamentais. As primeiras devem basicamente ser fundadas no consenso, enquanto as outras seguem o princípio da maioria."GARRETón (1994). Uma formulação tão razoável quanto distante da realidade latino-americana.

A dinâmica dos sistemas políticos pós-redemocratização produziu uma notável convergência no plano macroeconômico, mas não tem conseguido ultrapassar este patamar de processamento de conflitos (exceto o Chile, à luz de seu conjunto de particularidades).

O baixo grau de institucionalidade da administração pública de origem ibérica tem facilitado a recorrente captura de setores do Estado por interesses privados, freqüentemente dotados de forte representação política (bancadas próprias, controle de meios de comunicação, hegemonia em anéis burocráticos estratégicos etc.).

A novidade, no caso, é a crescente participação da tecnocracia (cuja ascensão se deu no período do autoritarismo, seja no governo ou 
na oposição - em especial nas universidades) no jogo político.

Os planos de estabilização projetaram estes novos híbridos nos cenários nacionais, redefinindo (...)

"O tecnocrata enquanto político torna-se um ator político e está envolvido no processo político no qual ele ou ela deve fazer ou influenciar as políticas. Os políticos, mesmo os tecnocratas, não podem agir no sistema pelo lado de fora, sendo eles mesmos atores em um campo complexo de forças em conflito composto por muitos outros atores, notadamente nos países democráticos." (BRADFORD JR, 1994).

De qualquer forma, a principal fonte de inovações e mudanças na esfera pública permanece sendo a classe política, cuja renovação efetiva só começou recentemente, com o ocaso das antigas lideranças dos ciclos populistas pré-ditaduras. Oriundos especialmente das administrações municipais vitoriosas e dos setores empresariais mais competitivos, começam a despontar dirigentes de distintos matizes políticos. Estes possuem como traço comum o pragmatismo e a capacidade de criarem e explorarem zonas de compromisso que lhes asseguram ampliação da sustentabilidade necessária para a consolidação da estabilização macroeconômica. Já com relação ao enfrentamento de questões (ex: previdência) disruptivas de arranjos cristalizados ao longo de décadas, as coisas estão por se fazer.

\section{Indicações de possíveis rumos}

O desmantelamento institucional anterior aos processos de estabilização fragilizou o setor público em relação a um conjunto de importantes agentes políticos e econômicos. Os sindicatos vinculados ao funcionalismo público foram atropelados de forma drástica nestes processos, em que pese o fato de, aqui e ali, terem sido capazes de preservar direitos e conquistas. As privatizações (iniciativas tipo once and for all), movidas por pressões majoritariamente fiscais, estão andando na frente do desenvolvimento das competências reguladoras, o que confere expressiva dianteira aos grupos que estão assumindo alguns dos principais ativos do Estado vendidos ao setor privado.

O desmanche do aparato de governo deveria, em tese, facilitar a adoção de um programa de reformas. Um Estado menor, dentro de uma visão simplista de Estado mínimo, significaria problemas menores, de manejo mais fácil. Mas a reforma social, a modernização e profissionalização do serviço público e o déficit de infra-estrutura, entre outras, não são questões que se processam no vazio. É muito difícil realizar um corte que simplesmente abstraia o passado. Há um dilema em relação ao "Estado 
estoque": nem tudo pode ser privatizado ou terceirizado, e o que permanece, para além do aparato jurídico-policial — as funções econômicas e sociais desenvolvidas pelos setores finalísticos (desenvolvimento econômico, infra-estrutura, educação, saúde etc) — encontra-se em estado de desorganização e anomia. Reformar o Estado significa encaminhar simultaneamente processos de transformação e renovação de estruturas de um serviço público desorganizado, desprofissionalizado e marcado por elevada rigidez e baixíssima capacidade de resposta. Isto implica abrir espaços a partir da liberação de recursos imobilizados em funções ou setores inócuos.

Mesmo as agências internacionais de fomento reconhecem que esta não é uma transição simples e costumam possuir uma visão até certo ponto ingênua deste processo. "A forma de se administrar a transição de um serviço público com um quadro excessivo de funcionários, com baixa capacitação e desmotivado em direção a um serviço público menor, remunerado de maneira realista e profissionalizado, de um modo a não provocar resistências à mudança, ainda não é adequadamente compreendida." (WORLD BANK, 1994: 2)

Mascarar o caráter conflitivo das reformas de segunda geração significa subestimar a dificuldade e a complexidade dos confrontos e negociações envolvidas nesta tarefa. As práticas protelatórias, bem como a acomodação no tempo de uma série de medidas nesta área (que só começam a vigorar após o decurso de dilatados períodos de reajuste e transição) são indicadores deste timing. Os custos de oportunidade são diluídos e genéricos, de modo que as forças políticas hegemônicas, que se beneficiam do status quo vigente, resistem até o limite a mudanças que possam colocar em risco sua protegida situação.

Um primeiro aspecto a ser considerado na definição da estratégia da reforma é a formulação de uma agenda positiva, incorporando os ajustes necessários a partir de uma perspectiva propositiva e construtiva. A idéia é regenerar o Estado, criar as condições para que cumpra melhor suas funções, restabelecer seus vínculos com a sociedade da qual emana sua autoridade. O convencimento e persuasão da opinião pública, dos formuladores de políticas, dos tomadores de decisão, da própria máquina administrativa e, em especial, da cúpula dos poderes Legislativo e Judiciário depende da capacidade de demonstração de que as reformas são necessárias e desejáveis para que o país cresça e funcione melhor.

$\mathrm{O}$ alcance e a profundidade das reformas vão depender das alianças capazes de conferir credibilidade e sustentabilidade, ou seja, da capacidade dos governos mobilizarem apoios e recursos junto a outros sujeitos do processo social (ONGs, entidades de classe, mídia, setor produtivo, agentes políticos, segmentos da burocracia etc.). É preciso haver cumulatividade nestes esforços, bem como uma atenção especial à problemática da construção de institucionalidades neste processo. 
Um segundo tema ainda pouco explorado é a operacionalização da reforma dentro de uma perspectiva de rede. As concepções de reformas mais difundidas ressaltam uma gestão de caráter centralizador (às vezes, até autoritária), ampla, top-down e fortemente amparadas pela legislação existente (diferente da cultura observada). Redes funcionam de forma diferente. Baseiam-se na difusão da informação. O poder é flutuante, movendo-se por pólos flexíveis. Assenta-se sobre a informação. Favorecem a fluidez de inovações.

Os processos de formulação, decisão e implementação de políticas públicas tendem a se alinhar por convergências construídas em torno de consensos sociais gerados ao longo de décadas. Nas redes, é possível potencializar recursos, confrontar interesses, partilhar informações, acumular massa crítica e partilhá-la e buscar consolidar consensos sobre pautas mínimas. Estas convergências indicativas de trajetórias balizam e fortalecem os esforços de promoção de reformas.

Uma terceira questão diz respeito à contextualização e historicidade dos desafios experimentados pelos países latino-americanos. A discussão da reforma do Estado em curso na América Latina é distinta da observada nos principais países do G-7, embora haja alguns traços comuns. São países com histórias e culturas diversas. Reconhecer estas especificidades é condição preliminar para o diálogo e não o simples transplante de experiências, metodologias e modus operandi. Não é possível, por exemplo, tomar como equivalentes a crise do welfare state com a do populismo, ou a dos regimes autoritários, ainda que seja possível identificar elementos próximos, quando não coincidentes. Nestes termos é temerário falar de um receituário único para realidades diferenciadas e heterogêneas, mesmo na própria América Latina.

Um quarto recorte importante é a publicização do Estado, a busca de recuperação de sua dimensão republicana. "La transformación de las relaciones entre Estado y sociedad implica una externalización de la reforma. Ésta deja de consistir en un proceso principalmente intraburocrático, como ocurre con el mejoramiento administrativo, y pasa a ser, esencialmente, un nuevo tratado sobre los límites legítimos que deben trazarse entre ambas esferas. "(OszlaK, 1994: 57) Este movimento de "fuga para a frente", aliás para o universo social (em contraponto à opacidade burocrática), é estratégico para ampliar a sua permeabilidade ao jogo das interações sociais. Trata-se de uma repolitização de questões intramuros (estrutura da folha de pagamentos, composição da dívida, dinâmica tributária, execução orçamentária-financeira etc.), cuja apropriação de custos e dividendos não são claramente compreensíveis.

O quinto tema em torno do qual é importante orientar a ação diz respeito à focalização. $\mathrm{O}$ contraponto é a recorrente pulverização dos recursos a ponto de comprometer a produtividade dos gastos públicos. 
Mas o mais importante são as conseqüências de uma adequada definição dos campos de incidência das ações (ex: burocracia de linha ou setores pervasivos - planejamento, administração, controle e orçamento, entre outros), de modo a que os resultados sejam irradiados para outras áreas e setores da máquina administrativa. $\mathrm{O}$ efeito demonstração de projetos vitoriosos passíveis de generalização é ilimitado. Da mesma forma, mudanças de patamar na forma de organização do serviço e na atuação de funcionários públicos que operam na ponta, rapidamente, são reconhecidas e se disseminam imediatamente. São transformações infra-estruturais, redefinidoras de padrões. O aprendizado por imitação ou contágio é bastante comum na esfera pública. $\mathrm{O}$ foco assegura o comprometimento com resultados, não apenas com atividades.

Uma sexta área de inflexão no âmbito dos esforços de promoção de reformas refere-se à introdução de uma cultura de performance no âmbito do serviço público. Accountability significa também foco no desempenho, ruptura com a sistemática de diluição de responsabilidades típica do serviço público. O fomento de uma atuação balizada por indicadores, orientada para a produção de resultados e responsabilizável pelos seus atos (o que inclui premiação ou punição) é um desafio intrínseco à implementação das reformas pretendidas. Nem todas áreas de atividade do setor público possuem características que as tornam passíveis de mensuração, mas a maioria é mensurável. Isto significa que comparações (internacionais, inter-regionais, ao longo do tempo etc.) podem ser feitas, bem como o estabelecimento e a contratação de metas. Parâmetros, marcas e indicadores são ingredientes de uma outra cultura de gestão accountable e mais permeável ao controle pela sociedade e pelo próprio governo eleito.

Por último, não há como deixar de reforçar a importância do Estado em redefinir sua postura em relação a seus recursos humanos, sua principal fonte de despesas no orçamento e seu principal ativo, em termos de potenciais ganhos de produtividade. Sem profissionalização da gestão pública, até a própria condução das reformas fica prejudicada, dependendo sempre da qualidade do preenchimento dos cargos de recrutamento amplo. Sem a criação das condições elementares para formar, qualificar e instrumentalizar os quadros de elite do Estado, os fenômenos de rent-seeking continuarão se multiplicando, como o próprio World Bank indiretamente reconhece.

"Mecanismos explícitos foram adotados para atrair indivíduos altamente qualificados para o serviço público. Dentre eles, incluemse o recrutamento e a promoção baseados no mérito, a compensação baseada no incentivo e a elaboração de carreiras claramente definidas, reward-oriented. Tais mecanismos baseados na 
competição produziram competência. Também foram criados mecanismos para proteger os funcionários públicos da interferência política.” (WORLD BANK, 1994: 8)

\section{Conclusões}

Todos os assuntos mencionados convergem para a identificação da imprescindibilidade da formulação de uma política nacional de administração pública, capaz de referenciar e alavancar o esforço de reforma. Este, por sua vez, precisa ser seletivo, focalizado e articulado, de modo a assegurar maiores probabilidades de êxito, bem como ganhos de produtividade em termos dos recursos investidos.

A pilotagem da reforma a partir de um estratégia de comunicação social pró-ativa e assertiva, bem como a busca sistemática de parcerias capazes de conferir sustentabilidade às iniciativas empreendidas, são fundamentais para uma maior publicização da esfera pública. A dimensão republicana do Estado precisa ser continuadamente reiterada, sob pena de se ampliar o fosso que o separa da sociedade que, em tese, o lastreia.

A revolução gerencial na administração pública está apenas começando e já enfrenta consideráveis resistências. A ênfase em atividades, funções e procedimentos e o descompromisso com os resultados e produtos são práticas inadmissíveis em tempos de revolução tecnológica, abertura comercial e agravamento da exclusão social. Mas o Estado se ressente ainda da ausência de mediações instrumentalizadoras que lhe confiram maiores condições de êxito na transição e impasse em que se encontra.

Finalmente, há de se ressaltar o problema do protagonismo da reforma, e em especial das reformas de segunda geração. As chefias intermediárias são, sem dúvida, os personagens-chave deste enredo. A modernização do Estado depende de sua própria capacidade de gerar as condições indispensáveis para sua profissionalização.

Governance permanece sendo um conceito chave, desafiador dos dirigentes latino-americanos neste final de século. O desenvolvimento da capacidade do Estado governar-se e/ou ser melhor governado constitui a fronteira entre o movimento e a paralisia. 


\section{Referências bibliográficas}

BRADFORD JR, Colin I. (1994), "Redefining the role of the state: political processes, state capacity and the new agenda in Latin America," in Bradford Jr, Colin I. Redefining the State in Latin America. Paris: IDB/OECD.

Burki, Shahid Javed and Edwards, Sebastian. (1996), Dismantling the Populist State. Washington D.C.: World Bank.

FrISCHTAK, Leila L. (1994), "Governance capacity and economic reform in developing countries." World Bank Technical Paper 254, Washington.

Garretón, Manuel Antonio. (1994), "New State-Society Relations in Latin America." in Bradford Jr, Colin I. Redefining the State in Latin America. Paris: IDB/OECD.

KLIKSBERG, Bernardo. (1992), Como transformar o Estado: para além de mitos e dogmas. Brasília: ENAP.

LEISINGER, Klaus M. (1996), “A boa governança começa em casa,” in: Konrad Adenauer Stiftung (ed.), Desenvolvimento Econômico ou Humano? Reflexões sobre uma nova política de desenvolvimento. São Paulo: Konrad Adenauer Stiftung, p.39-90.

NAIM, Moises. (1994a), Instituciones: el eslabon perdido en las reformas economicas de America Latina, (mimeo), Bogotá.

NaIm, Moises. (1994b), "Public Bureaucracies in Developing Countries: ten paradoxes," in Chaudhry, Shahid Amjad, Reid, Gary James and Malik, Waleed Haider (eds.), Civil Service Reform in Latin America and the Caribbean. Washington: World Bank Technical Paper 259.

OszLAK, Oscar. (1994), "Estado y sociedad: las nuevas fronteras," in Bernardo Kliksberg, (comp.), El Rediseño del Estado. México: Fondo de Cultura Económica.

Shiнata, Ibrahim F. I. (1994). "Civil Service Reform in Developing Countries," in Chaudhry, Shahid Amjad, Reid, Gary James and Malik, Waleed Haider (eds.), Civil Service Reform in Latin America and the Caribbean. Washington: World Bank Technical Paper 259.

TomassinI, Luciano. (1994), "The IDB and the modernization of the State," in Bradford $\mathrm{Jr}$, Colin I. Redefining the State in Latin America. Paris: IDB/OECD.

World BAnK. (1992), Governance and Development. Washington: The World Bank.

World BANK. (1994), Governance: The World Bank's Experience. Washington: The World Bank. 
A reforma do Estado no contexto latino-americano: comentários sobre alguns impasses e possíveis desdobramentos.

Francisco Gaetani

$\mathrm{O}$ artigo se constitui em uma reflexão sobre a reforma do Estado nos países latinoamericanos, em especial no que se refere a seu aparato institucional - a "máquina administrativa".

Identificadas como reformas de $2^{\underline{a}}$ geração (as de $1^{\underline{a}}$ são as do reajuste macroeconômico), o conjunto dos esforços modernizadores busca a regeneração das instituições públicas duramente afetadas pela crise econômico-financeira dos anos 80 , e/ou até mesmo a criação de novas instituições, visando a construção de um Estado forte, apoiado em uma economia dinâmica e competitiva, da qual é parceiro e regulador, além de desempenhar de forma adequada suas funções clássicas.

$\mathrm{O}$ autor discute as questões institucionais e sociais (accountability, governance, conexões entre as reformas econômico-financeiras), a mudança de paradigma do papel do Estado e os desafios a serem enfrentados.

\section{La reforma del Estado en el contexto latinoamericano: comentarios sobre algunos impasses y posibles desarrollos.}

\section{Francisco Gaetani}

El artículo constituye una reflexión sobre la reforma del Estado en los países latinoamericanos, especialmente en lo que se refiere a su aparato institucional -- la "máquina administrativa".

Identificadas como reformas de 2a generación (las de 1a son las del reajuste macroeconómico), el conjunto de los esfuerzos modernizadores busca la regeneración de las instituciones públicas, duramente afectadas por la crisis económico-financiera de los años 80 , y/o incluso la creación de nuevas instituciones, con miras a la construcción de un Estado fuerte, apoyado en una economía dinámica y competitiva, de la cual es socio y regulador, además de desempeñar sus funciones clásicas de forma adecuada.

$\mathrm{El}$ autor discute las cuestiones institucionales y sociales (accountability, gobernación, conexiones entre las reformas económico-financieras), el cambio de paradigma del rol del Estado y los retos que han de enfrentarse.

\section{The state reform in the Latin-American context: comments on some dilemmas and their possible developments.}

\section{Francisco Gaetani}

The article offers a reflection on the state reform in Latin-American countries, particularly in respect to their institutional apparatus - the "administrative machine". Referred to as second-generation reforms (the first generation covers macroeconomic adjustments), these modernizing efforts aim at the rebuilding of those public institutions hardly affected by the financial - economic crisis of the 80s, and / or the creation of new ones. This would enable the set up of a strong State, which holds up on a dynamic and competitive economy where it acts both as partner and regulator, but also performs its traditional tasks in an adequate manner. The author raises institutional and social issues (accountability, governance, relationship between economic-financial reforms), the change of paradigm about the State role and the challenges to be met.
Ano 49

Número 2

Abr-Jun 1998 